\title{
Etnoconhecimento Terena na literatura científica: um estudo bibliográfico para o Estado da Arte
}

\author{
Paulo Roberto Vilarim 1 (i)
}

Universidade de Coimbra, CFisUC - Centro de Física da Universidade de Coimbra

\author{
Décio Ruivo Martins 2
}

Universidade de Coimbra, CFisUC - Centro de Física da Universidade de Coimbra

Sérgio Paulo Jorge Rodrigues 3 (iD)

Universidade de Coimbra, CQC, Departamento de Química

Dossiê | Dossier | Dosier

\section{DOI do artigo: 10.22481/odeere.v6i2.9768}

RESUMO

O povo Terena é uma etnia indígena com vasto material de pesquisa e com um número de membros Terena que são pesquisadores e que produz um número considerado de material científico. Atualmente os Terena são uma população de cerca de 28 mil indivíduos no estado do Mato Grosso do Sul (MS) e que se distribuem por várias terras indígenas em todo o estado, além de outras em São Paulo e Mato Grosso, bem como em diversas cidades. Sua produção cultural e científica estão em estudo e boa parte destes estudos estão nas plataformas científicas. Este artigo faz o Estado da Arte deste etnoconhecimento, num estudo de revisão sistemática da bibliografia com três descritores: Conhecimento Tradicional, Etnoconhecimento e Terena, onde os dois primeiros são sinônimos e se relacionam com o terceiro. Neste estudo sistemático nos traz a luz as publicações e autores que estudaram e estudam a arte, a ciência e a cultura Terena. Há um amplo conhecimento científico nos conhecimentos tradicionais que há gerações vem sendo passado entre os Terena, parte deste conhecimento está no estado da arte aqui apresentado.

Palavras chave: Terena, Conhecimento tradicional, Etnoconhecimento, Arte, Cultura.

\section{Terena ethnoknowledge in scientific literature: A bibliographical study for the State of the Art \\ ABSTRACT}

The Terena people are an indigenous ethnic group with vast research material and with a number of Terena members who are researchers and who produce a considerable number of scientific material. Currently, the Terena are a population of about 28 thousand individuals in the state of Mato Grosso do Sul (MS) and are spread over several indigenous lands throughout the state, in addition to others in São Paulo and Mato Grosso, as well as in several cities. Its cultural and scientific production are under study and most of these studies are on scientific platforms. This present article presents the State of the Art of this ethnoknowledge, in a systematic review study of the bibliography with three descriptors: Traditional Knowledge, Ethnoknowledge and Terena, where the first two are synonymous and are related to the third. This systematic study brings to light the publications and authors who studied and study Terena's art, science and culture. There is extensive scientific knowledge in the traditional knowledge that has been passed on for generations among the Terena, part of this knowledge is in the state of the art presented here

Keywords: Terena, traditional knowledge, Ethnoknowledge, Art, Culture

Submetido em: 28/10/2021 | Aceito em: 24/11/2021

\footnotetext{
1 Professor de Física do IFMS/CG. Bacharel em Física na Universidade Estadual de Maringá (UEM), Licenciado em Física na UTFPR, Mestre em Física da Matéria Condensada na UEM e Doutorando em História da Ciência e Educação Científica pela Universidade de Coimbra (UC).E-mail: paulo.vilarim@ifms.edu.br

2 Doutoramento em História e Ensino da Física pela Universidade de Coimbra. Tem diversos trabalhos publicados sobre História da Ciência e Etnociência. Pertenceu à Comissão científica do Museu da Ciência da Universidade de Coimbra. É coordenador do Curso de Doutoramento em História das Ciências e Educação Científica da Universidade de Coimbra.E-mail: decio@uc.pt

3 Doutorado em Química e professor da Universidade de Coimbra. A sua área de investigação é a química teórica e computacional e as suas aplicações em química ambiental, astroquímica e química medicinal. Tem também interesse pelo ensino e história da química, assim como pela divulgação e comunicação de ciência. E-mail: spjrodrigues@gmail.com
} 
1.0- O estado da arte e sua importância na construção da pesquisa

O Estado da Arte é uma sistematização da pesquisa exploratória por meio de revisão bibliográfica em bancos de dados de artigos, teses e trabalhos acadêmicos. Através de descritores selecionados das categorias analíticas para coletas de dados que auxiliam as pré-análises do quadro do referencial teórico que estabelecem indicadores que constituem o corpus de análise. Nesta revisão busca-se identificar autores, textos e teorias que contribuam para construção da pesquisa que está sendo realizada para o doutorado. Este mapeamento de uma fatia do conhecimento dos bancos de dados fundamenta e edifica a exploração dos conhecimentos em determinado grupo de descritores de formação da pesquisa (Ferreira, 2002; Romanowski e Ens, 2006).

No Estado da arte é importante definir as limitações de tempo, descritores, bancos de dados e captação de dados para a pesquisa. Focar em descritores que fundamentam a pesquisa é essencial para definir um limite na própria pesquisa. Outro importante ponto de análise é o recorte temporal e as fontes de pesquisa que podem limitar ou ampliar sua análise. As relações entre os descritores e seus sinônimos são importantes na delimitação à busca e na colimação dos dados, pois é importante ao pesquisador ter um panorama amplo e das pesquisas realizadas, dos autores e teorias que são propostas na área de concentração da pesquisa. É um trabalho árduo a seleção e leitura dos materiais selecionados, entretanto importantíssimo na pavimentação do conhecimento.

Neste recorte do Estado da Arte pretende-se apresentar, de forma estruturada, a literatura científica em torno da relação entre em descritores, dos quais dois em comum, a citar "Etnoconhecimento" e "Conhecimento Tradicional" (CT) e que se sobrepõem, praticamente como sinônimos, a se somar com um terceiro descritor "Terena". Todos pesquisados entre aspas para não se confundir ou ampliar para outros termos, além da utilização dos operadores booleanos AND - OR. As buscas não se restringiram as áreas de conhecimento específicas dos grupos de pesquisa e/ou data de publicação. Por tanto, a busca foi realizada utilizando "Terena" AND/OR "Conhecimento Tradicional", "Terena" AND/OR "Etnoconhecimento".

Observou-se que ao utilizar o operador booleano AND os arquivos encontrados eram restritos e escassos, mas ao utilizar o operador OR a pesquisa 
ampliava, por este motivo optou-se por utilizar o operador OR.

Foram filtrados os arquivos coletados gerenciando as referências para separá-las, excluir os trabalhos em duplicidade ou que não se identifiquem com os critérios de seleção. Muitos autores e pesquisadores Terena surgiram, a maioria dos trabalhos voltados a educação escolar indígena, arte e cultura Terena.

Diante do exposto, privilegiamos as maiores bases dados, a exemplo: Scielo, Researchgate, Biblioteca Digital Brasileira de Teses e Dissertações (BDTD), entre outros.

A leitura dos resumos nos possibilitou a seleção dos textos, artigos e teses que, em princípio, nos remetia ao tema de interesse de modo que a leitura completa destes textos permitiu a seleção e catalogação a fim de assegurar a relevância do estudo, pesquisa que pretendemos realizar mediante a importância do tema para o mundo contemporâneo além do seu caráter inédito e autêntico.

Salienta-se que o estado da arte é uma pesquisa evolutiva e sem tempo para acontecer, e até o final da escrita de qualquer trabalho outras pesquisas podem ocorrer para acrescentar, atualizar e ampliar a pesquisa.

2.0- Os Terena e um pouco da sua origem e história no MS.

Segundo o Instituto Brasileiro de Geografia e Estatística (IBGE - 2010) o estado do Mato Grosso do Sul (MS) abriga a segunda maior população indígena do Brasil (73.295), são oito etnias: Atikum, Guarani Kaiowá, Guarani Ñandeva, Guató, Kadiwéu, Kiniquinau, Ofaié e Terena. No estado do Amazonas (168.680) está à primeira. A terra indígena mais populosa no país é a Yanomami, com 25,7 mil habitantes ( $5 \%$ do total) distribuídos entre o Amazonas e Roraima. Já a etnia Tikúna (AM) é mais numerosa, com 46 mil indivíduos. Em seguida, vem a etnia Guaranikaiowá (MS), com 43 mil índios e os Terena estão em torno de 29 mil indivíduos.

O povo Terena é descendente dos Txané-Guaná da família linguística dos Aruak. A língua Aruak, para os Terena, não é usada como imposição de cultura, e sim, apenas no processo de comunicação. Em verdade (...) "os Terena têm orgulho de dominarem, inclusive por meio do uso da língua do purutuyé (corruptela de português, língua dos brancos), a situação de contato com a sociedade nacional, e é este domínio que lhes permite continuar existindo enquanto um povo, política e administrativamente autônomo" (Bittencourt e Ladeira, 2001, p.130). 
Até o final do século XIX, os povos indígenas estavam separados e se distinguiam entre si, em vários povos: Terena (ou Etelenoé), Echoaladi, Quiniquinau (Equiniquinau) e Laiana. Todos da região do Chaco/Pantanal de 700 mil quilômetros quadrados, que engloba, Brasil, Paraguai, Bolívia e Argentina. "Os antigos Guaná falavam, até o período anterior à guerra entre o Paraguai e a Tríplice Aliança (1864-1870), diversos dialetos Aruák. Estavam divididos em Terena (Etelenoé), Echoaladi, Quiniquinau (Equiniquinau) e Laiana (Layana)." (Oliveira e Pereira, 2003, p. 242).

Os Terena, por contarem com uma população bastante numerosa e manterem um contato intenso com a população regional, são o povo indígena cuja presença no estado se revela de forma mais explícita, dentre outras razões, por estarem localizados na região da capital do estado, Campo Grande/MS. Podemos citar o cacique do povo Terena Enio de Oliveira Metelo "Eu posso ser o que você é sem deixar de ser o que eu sou!". No curso da História do Brasil os Terena se adaptaram a guerras e a novas mudanças de território sem perder sua cultura e sua identidade. Uma parte dessa identidade está na sua mitologia, arte e vasta cultura.

3.0- O etnoconhecimento Terena no estudo Bibliográfico: Sua arte e sua ciência na literatura científica.

Quando se fala em etnoconhecimento Terena ou Conhecimento Tradicional Terena, perpassamos na história da cultura Terena de integração familiar e da transmissão oral na educação diária. O "Tronco Velho" (Ancião) tem um papel importante na transmissão desta cultura e da integração da educação escolar indígena nos costumes e sabedorias étnicos. Para Miranda (2006), essa preocupação pode ser afastada, pois:

[...] nas comunidades Terena este aspecto é muito importante no sentido de ensinar e educar as novas gerações quanto aos saberes tradicionais que ainda existem nas comunidades, iniciando com a participação dos mais velhos nas orientações sobre a natureza, sobre a cosmologia e sobre o mundo, mas, ao mesmo tempo, percebe-se um grande interesse da juventude em entender melhor o mundo científico, das ciências dos nãoíndios. (Miranda, 2006, p. 86) 
O conhecimento tradicional é amplamente mencionado e discutido nos textos seja por sua definição simples dos fatos da tradição oral ou pela comunicação entre os membros Terena e sua propagação de conhecimento. Ficando claro para Domingo (2017, p. 72) que o Terena não fica parado no tempo, ele evolui, acompanha a modernidade, mas traz consigo os saberes, os costumes tradicionais, ajustados a esta modernidade, como é o caso da lida com a terra, usa a tecnologia disponível, mas se orientando pelos costumes tradicionais, conforme sua crença. Nessa mesma linha de pensamento Seizer da Silva (2016, p. 19), afirma "Reinventamo-nos, estabelecemos novas conexões com outros saberes, nos tornamos Terena com memória cosmológica "cristalizada" nos saberes dos meus avós maternos."

Porém, Cunha (2007, p. 78) afirma que o conhecimento científico e conhecimento tradicional além de serem diferentes, são incomensuráveis, mas os dois são formas de entender e agir sobre o mundo. E ambas são também obras abertas, inacabadas, sempre se fazendo. Para Posey (1986), compreende-se que o conhecimento indígena não se enquadra nas classificações e subdivisões precisamente definidas como as que a ciência ocidental tenta artificialmente organizar. Brostolin (2009, p.26-27) assevera que "neste sentido, urge o conhecimento e a valorização do processo histórico educativo vivido nas famílias e na comunidade estabelecendo o intercâmbio entre os saberes tradicionais e os novos conhecimentos".

O conhecimento das populações tradicionais ou etnoconhecimento é transmitido de geração em geração. É um saber passado pelas relações de parentesco e vivência. As crianças aprendem com os adultos, quando os acompanham nas atividades diárias. Alguns conhecimentos são passados para os mais jovens, por considerarem que há maior necessidade, como, quais os recursos extraídos da natureza que podem ser utilizadas contra picada de animais peçonhentos, etc. Outros conhecimentos como a cura de enfermidades com o uso das plantas são repassados a homens, mulheres e crianças com maior aptidão para o assunto (Fraxe et al.,2007, p. 96-97).

Deste modo, o etnoconhecimento não está apenas na figura de um Xamã ou no líder de uma tribo ou aldeia, mas no diálogo entre os indivíduos constituintes de toda a comunidade indígena ou não indígena. Para Rové (2000), as "etnociências" vêm, assim, como princípio epistemológico a fornecer uma via para 
o estudo do "pensamento científico" em "culturas tradicionais" Portanto, o etnoconhecimento não está apenas vinculado aos povos originais, e sim está na perpetuação da propagação continua dos conhecimentos tradicionais do cotidiano de uma comunidade ou grupo.

No que tange aprender a conhecer, aprender a fazer e aprender a viver em conjunto, Elizabeth Ann McKinley e Linda Tuhiwai Smith (2019), no livro Handbook of Indigenous Education, há uma perspectiva da educação e do conhecimento indígena que podemos trazer para a realidade brasileira e mundial. "A invasão e a exploração colonial destruíram os conhecimentos indígenas e as formas de conhecimento e, como resultado, as peças foram espalhadas - destruídas, ocultas e outras partes apenas esperando para serem reconstruídas". Os educadores indígenas e as comunidades passam a tomar a frente nos processos de escolarização. Segue o trecho em destaque:

\begin{abstract}
A educação indígena nem sempre foi marginalizada. As comunidades indígenas sempre mantiveram e desenvolveram sistemas educacionais complexos. Por exemplo, tradicionalmente na sociedade maori em Aotearoa Nova Zelândia, haviam instituições de ensino superior, os estudantes eram especialmente escolhidos para desempenhar papéis especiais em suas comunidades, as crianças eram desenvolvidas e seus interesses particulares eram observados. O aprendizado foi elevado acima das atividades comuns de uma comunidade, tinha elementos espirituais e havia rituais e protocolos a serem observados. A invasão e a exploração colonial destruíram os conhecimentos indígenas $e$ as formas de conhecimento e, como resultado, as peças foram espalhadas - destruídas, ocultas e outras partes apenas esperando para serem reconstruídas (Mckinley e Smith, 2019).
\end{abstract}

\title{
4.0- A cultura e a arte Terena
}

Um dos grandes elementos da cultura Terena relatado na literatura acadêmica é a cerâmica. A cerâmica é o primeiro material sintético criado pelo o homem e de enorme importância na história da humanidade estando presente em cerimonias e no seu dia-a-dia. O termo "Cerâmica" vem do grego keramos, significa "material queimado" ou "louça de barro".

O reconhecimento da importância da cerâmica Terena, em Mato Grosso do Sul, pode ser ilustrado pelo fato de ter sido registrada como patrimônio imaterial histórico, artístico e cultural, pelo Governo do Estado, por meio do decreto normativo No 12.847, de 16 de novembro de 2009 (MATO GROSSO DO SUL, 2009). 
O referido decreto de 2009 determina o registro da cerâmica Terena como patrimônio imaterial de MS, a saber:

Art. $1^{\circ}$ Fica registrada a Cerâmica Terena como patrimônio imaterial histórico, artistico e cultural do Estado de Mato Grosso do Sul.

Art. $2^{\circ} \mathrm{O}$ bem imaterial, Cerâmica Terena, será registrado no Livro de Registro dos Saberes, nos termos do inciso I do art. 16 da Lei $n^{\circ} 3.522$, de 2008, onde são inscritos conhecimentos e modos de fazer enraizado no cotidiano das comunidades. (MATO GROSSO DO SUL, 2009).

Para Castilho et al. (2017, p. 196), a cerâmica Terena é um elemento agregador junto com a Língua, colaborando de forma significativa para a preservação e testemunho da herança cultural dessa etnia. Um discurso de resistência, passado de geração em geração, e sendo um exemplo vivo da força identitária construída pelas mãos sábias de mulheres que perpetuam modos e saberes.

Confirmado por Lima (1987), ao informar que a cerâmica indígena brasileira está ligada a área doméstica, constituindo domínio quase exclusivamente feminino, e a mulher Terena, exceto na estação chuvosa ou em lugar de difícil acesso, tem o auxílio masculino na coleta do barro. "Em dia que se vai fazer cerâmica não se vai para a cozinha", afirmação da ceramista Terena.

Assim, segundo Gomes e Kabad (2008, p. 8) a cerâmica, entre os Terena, é um trabalho essencialmente feminino e as mulheres seguem as seguintes regras na sua produção: nos dias em que vão fazer cerâmica elas não vão para a cozinha, pois acreditam que "o sal é inimigo do barro" (para eles, o sal anula as propriedades do barro); além disso, não trabalham quando estão menstruadas (sob o risco de ameaçar o resultado final); e nem durante a lua nova (os índios Terena acreditam que a cerâmica é governada pela lua: a lua manda e a cerâmica sai da terra). Estas interdições são características do processo ritual da fabricação dos artefatos de barro e visam limitar o contato entre o sagrado e o profano.

Em 1883, em expedição na aldeia dos Terena, Rohde percebeu várias peças de barro, de todos os tamanhos e formas, confeccionadas por homens e mulheres, depositadas no chão ou penduradas. O modelo e a pintura ficavam exclusivamente a cargo das mulheres.

Em 1946 Altenfelder, esteve nas aldeias dos Terena e constatou que o 
processo de produção dos potes de cerâmica era por espirais de argila de cor vermelha como relatado em 1883. Os potes eram ornamentados com desenhos brancos e pretos. Os vasos e os potes eram cozidos após serem pintados com resina de jatobá. (Altenfelder, 1949, p. 295) vale ressaltar que a produção da cerâmica mantém mesmo princípio até a atualidade.

A cerca das cores existe um padrão que desde os mais antigos relatos segue um padrão de obtenção dos pigmentos e do tratamento na execução da sua confecção. Mais recentemente há relatos em Gomes $(2008,2016)$ e Sebastião (2012) sobre a obtenção dos pigmentos e na importância na constituição dos artefatos. Em Gomes (2016), descreve os nomes em Terena e os locais de obtenção destas cores:

\begin{abstract}
A primeira delas é o harará 'iti moté, o barro vermelho, usado para recobrir as peças, funcionando como uma pintura. A segunda é o káta, conhecido como caulim, uma argila branca encontrada no fundo das lagoas, utilizada para fazer os padrões decorativos característicos dessa arte por lembrarem uma renda. Recentemente algumas oleiras têm utilizado uma pedra preta que, dissolvida na água, funciona como pintura também. (Gomes, 2016)
\end{abstract}

A constituição da argila permite seu manuseio pela plasticidade. Minúsculos grãos de cerâmica, anteriormente preparados a partir de peças quebradas ou rejeitadas após a queima, o tempero regula a plasticidade do barro (Barbosa, 2003; Dias, 2007; Graziato, 2008; Gomes e Kabad, 2008; Gomes, 2016). Conforme Dias (2007), a oleira introduz o antiplástico (em Terena akâruke) na argila a fim de modificar a estrutura física do barro, preparando uma massa que propiciará o desenvolvimento do seu trabalho. Gomes (2016) nos informa que o akâruke pode ser formado por várias substâncias, como tijolos, barro queimado, cacos cerâmicos, que somadas à argila pura e extremamente plástica, serão responsáveis por dar liga à matéria-prima original.

Há de se observar que as mãos devem estar limpas, sem vestígios de suor ou gordura, pois podem prejudicar e trincar as peças. Segundo Gomes (2016) [...] "precauções relacionadas a substâncias e intencionalidades, físicas e metafísicas, que podem afetar a cerâmica em transformação[...], impedido de entrar em contato com determinados elementos, uma vez que seu corpo frágil não suportaria a ação de agentes externos." Após o polimento, são pintados os desenhos com pigmentos de argila e água. Para finalizar o processo de fabricação a cerâmica 
deve ser queimada até perder toda a água e secar. Ao secar, a argila perde plasticidade e surgindo a cerâmica que será pintada posteriormente, possivelmente com a utilização de pigmentos minerais lóxidos de ferros e manganês) para pintura das cerâmicas.

Para conferir dureza e resistência à cerâmica é necessário que a temperatura da queima seja segundo, Godoy (2001), entre $800^{\circ} \mathrm{C}$ e $1.100^{\circ} \mathrm{C}$. Em geral os fornos são buracos rasos, cavados próximo ao local em que as ceramistas produzem as peças (Vietta, 2015, p. 114). Para Chaves (2019) na aldeia Cachoeirinha, a temperatura máxima atingida não ultrapassou $550^{\circ} \mathrm{C}$. Em Gomes (2016) descreve o processo de evaporação e secagem desta forma: "Para controlar a água que evapora da argila e garantir sua invisibilidade, essa jarra foi colocada dentro de um saco plástico".

Os motivos dependem das mãos e inspiração dos artistas, podendo ser flores e animais, entre outros e são pintados com pincéis improvisados de pena. As peças são expostas ao sol, para secar num processo que pode durar até uma semana. Castilho (2017, p.194) nos informa que os produtos da terra e a própria terra/barro transformada em cerâmica é uma das principais formas de testemunho de herança cultural Terena. São potes, cumbucas, travessas e figuras zoomórficas com delicados adornos florais e pequenos traços geométricos que seduzem e encantam pela beleza e singularidade.

Para a obtenção da argila ou confecção da cerâmica, é importante a passagem temporal e os efeitos cosmológicos, como citado por (Souza, 2000; Barcelos Neto, 2008; Gomes, 2008, 2016). Em Gomes (2016, p. 76, 172, 173) cita que no caso de muita chuva, vento ou do surgimento da lua nova, a ceramista necessitará ficar sem manusear as peças por muitos dias, o que significa que não poderá dosar a umidade dos objetos. Como a tendência do corpo argiloso é perder água, os envoltórios, além de protegerem a arte de barro, constituem técnicas de regulação da água que entra e sai do corpo cerâmico. [...] "Dizem que a argila coletada na estação da lua nova racha ou estoura na hora da queima." Barcelos Neto (2008) menciona casos de objetos que tem sua agentividade potencializada em ocasiões de eclipses e outros fenômenos celestes.

As transações lunares e os marcos temporais são de grande importância na construção de uma agricultura na cultura Terena, tais marcos temporais definem suas etapas de plantio e colheita Influenciadas com o conhecimento tradicional 
pela observação da natureza e das constelações como a já muito conhecida constelação da Ema. Os Terenas construíram uma agricultura consistente que influenciam toda a comunidade e seus ritos e costumes, a citar: (Terena, 2003; Oliveira, 2003; Fehlaver, 2004; Cardoso, 2007; Afonso 2006; Miranda, 2006; Afonso e Silva, 2012; Ortiz, 2014; Domingo, 2017; Nascimento, 2020) além de (Fialho, 2010; Galdino, 2011; Langhi, 2011).

Em Domingo (2017) os Terena marcam o início e o fim do ano pelo plantio e pela colheita, assim como a primavera (abobora e melancia), outono (feijão), verão (arroz, colheita da guavira e melancia) e inverno (colher feijão, mandioca e cana). Uma das técnicas utilizadas é citada em Fehlaver (2004, p. 112-113) Um método indireto para diminuir os problemas com carunchos, especificamente para as culturas de feijão, arroz e milho consiste, segundo os informantes, na colheita durante o período compreendido entre as fases da lua crescente e minguante.

Em Miranda (2006, p. 84) o relato do Sr. Dionísio retrata a importância da observância da natureza "[...] Para nós um indicador importante para sabermos se no próximo ano teremos uma boa safra de alimentos é só observar na mata os ipês (Tabebuia sp.):

[...]se estiverem floridos em setembro, época de preparo do solo nas aldeias, a natureza está nos dizendo que a produção será boa no próximo ano, mas se não florirem, temos que trabalhar muito para guardarmos alimento, pois no próximo ano teremos dificuldades com a produção [...] (Dionísio Miranda, 91 anos, Terena da Aldeia Água Branca, Nioaque-MS, Miranda, 2006).

Da cultura e arte Terena se destaca autores como Jesus 2007 e 2014; Cunha, 2018; Cunha e Paiva, 2018; Oliveira, 2016. Meliá (1979, p. 11), nos informa que a "educação indígena é ensinar e aprender a cultura, durante toda a vida em todos os aspectos[...]. Para Bittencourt e Ladeira (2000, p.11), os Terena "possuem ou possuíram formas de organização internas características, sendo tradicionalmente agricultores e conhecedores das técnicas de tecelagem e cerâmica".

Da tecelagem Terena, Rohde em 1883, observou que as índias andavam com redes presas na testa, uma faixa e várias cabaças de água. Faixas tecidas, segundo o autor, com muito gosto e paciência. Uma rede poderia levar até seis meses para ser fabricada, isso se deve ao fato de primarem pela durabilidade e resistência, além da originalidade. Essas peças não eram trocadas 
por outras peças de algodão. Em sua maioria, eram brancas com motivos azuis e vermelhos. Em relação das cores Rohde (1990), explana:

[...] eles conseguem de uma planta, que chamam de Uito (certamente 'Indigo'). As ramas e folhas da referida planta são cozidas e o algodão mergulhado nessa água. A lã vermelha, que é usada frequentemente (sic) na sua tecelagem, procede de flanela vermelha, que compram em Miranda. Essa flanela é cortada em pedaços, desmanchada em flocos e depois fiada novamente. (Rohde, 1990, p. 13).

O que se sabe sobre o ato de tecer é que não há um consenso quanto à data exata de seu surgimento. Alguns estudiosos da área indicam que ocorreram ainda no Paleolítico nas Cavernas da Criméia, onde placas de ossos crivadas com pequenos orifícios foram encontradas e foram identificados como teares. Outras fontes apontam o surgimento da tecelagem no final do período Mesolítico, cerca de 5000 a.C. O que se conhece hoje é que as fibras mais antigas são a lã, com achados de cerca de 7000 a.C., seguido pelo linho, com achados em escavações de antigas civilizações lacustres da Ásia central e ocidental datando de 6000 a.C. (Silveira, 2013)

No Brasil o primeiro documento que comprova a manufatura de tecidos é a Carta de Pero Vaz de Caminha ao rei Dom Manuel (1469-1521): "a uma mulher moça com um menino ou menina ao colo, atado com um pano não sei de quê aos peitos", e "as casas tinham dentro muitos esteios e de esteio a esteio uma rede, atada pelos cabos em cada esteio".

Segundo Stein (1979, p. 57), o algodão já era tecido pelos índios antes da chegada dos portugueses. Ainda, Ribeiro (1983) comenta que no Brasil, os povos indígenas fazem uso de materiais de origem vegetal - madeiras, cipós, enviras, palhas, fibras, resinas, óleos, sementes, caniços - para edificarem suas moradias e na produção de artefatos de uso cotidiano e ritual. A arte de trançar fibras vegetais representa a mais diversificada das categorias artesanais indígenas pois revela adaptações ecológicas e expressões culturais distintas (Ribeiro, 1987)

Segundo Geertz (1997), a arte é uma forma de comunicação em uma sociedade, que transmite a história, a tradição e trazem os elementos que dinamizam os costumes dentro de um grupo. A etnociência está na transmissão desta técnica à próxima geração. Culturalmente os índios Terena mantem a tradição do tear para que as novas gerações possam, de forma genuína, aprender 
como os antigos produziam suas vestimentas e utensílios.

Em 1946, Altenfelder observou que a tarefa continuava feminina, acrescentada de formas diferentes na fiação. Eram empregadas fibras de algodão, de palmeiras e de um arbusto chamado yuhi. Utilizavam um fuso de madeira que variava de tamanho conforme a espessura das fibras que eram deixadas de molho por alguns dias na água para serem separadas facilmente e fiadas depois de secas. Com essas fibras confeccionavam bolsas para guardar frutas e objetos, sendo as maiores para o transporte de produtos da roça. (Altenfelder, 1949, p. 295)

Em 1949, Oberg cita que era utilizada a fibra da planta yulu, uma espécie de bromélia. Mergulhavam as folhas em água para amaciar e as fibras eram separadas em fios e fiadas no fuso de madeira; assim como o algodão. O tecelão começava de debaixo para cima e era desnecessário o corte do tecido, pois a trama, a cada volta, era virada para trás.

Rohde, em 1883, observou também o trançado de palhas na confecção de chapéus (confeccionado de folhas secas de uma palmeira de leque chamada carnaúba) e cestos (confeccionado de bambu partido ao meio), normalmente trançado pelos homens. Vale salientar que o trançado não é um ato espontâneo, pois é necessário que regras sejam obedecidas além do domínio de técnicas. Neste sentido Altenfelder, em1946, observou que os Terena fabricavam cestos e abanicos de carandá ( $O$ carandá (Copernicia Alba) é uma palmeira comum no Pantanal) ou de bambu, utilizados para guardar e transportar alimentos ou ainda para transportar crianças

Também podem citar o trançado dos abanicos, utilizados como leque para amenizar o calor, aumentar ou fazer o fogo "pegar" no deslocamento de ar. É transmitido o seu ensinamento entre as gerações pela mulher. (Altenfelder, 1946). Esse trançado é feito até hoje com a fibra vegetal do buriti.

Os mais antigos relatam que utilizavam colchões feitos de fibras trançadas, macias, que cobriam suas camas, chamadas de giraus, um trançado de madeira elevado do solo. Esta produção citada por Oberg (1949), relata que os Terena faziam cestos, abanadores e chapéus de pequenas tiras de bambu, carandá e de piri.

Segundo Sá (2012, p. 148), existe o trançado com a taboa (Typha dominguensis) que é encontrado em terrenos alagadiços, próximo à aldeia 
Passarinho, da região da cidade de Miranda onde o mesmo processo se repete: colher talos verdes, secar ao sol para garantir a resistência e flexibilidade. São trançados em cordões e, com eles, podem ser confeccionados chapéus, bolsas, cestos, etc. Nessa mesma região, é utilizado também o pindó (Syagrus romanzoffiana) para confecção de cestos, bolsas, tapetes e roupas especiais para a Dança do Bate-Pau. (SÁ, 2012, p. 154).

Segundo Silva e Vidal (1995, p. 391), "a arte do trançado é uma das mais antigas manufaturas que a humanidade conhece e representa a mais diversificada das categorias artesanais indígenas no revelar adaptações ecológicas e expressões culturais distintas [...] dizem, e com razão, que as sociedades indígenas do Brasil representariam a civilização da palha".

Atualmente, a tecelagem e o trançado caíram no desuso nas aldeias, pois os produtos industrializados estão cada vez mais presentes, inseridos nas casas dos Terena. Nos textos estudados mais recentes nada foi encontrado a cerca da tecelagem ou trançado. Não é sabido, se as técnicas estão em desuso ou não houve interesse científico em estudar esses aspectos da cultura Terena.

Neste caminho, algumas falas se destacam dos autores e pensadores Terena, em Lima (2006, p.14) destaca que ao "contrário do que muitos pensam, a comunidade indígena não é uma comunidade em decadência, mas uma comunidade que se relaciona com o mundo que a circunda; ela dialoga de maneira que thes é própria, como, por exemplo, a relação com o dinheiro e com a terra." E na fala de Marcos Terena (2003) do ato de duvidar do próprio conhecimento tradicional e da preocupação da preservação da tradição:

Quando eu era guri, eu conhecia algumas plantas medicinais, aquela caixinha de emergência que a gente usa no carro, vamos chamar assim, a gente também tinha isto. Um dia cortei o pé, lá em Campo Grande, e eu conhecia a planta para cicatrizar, para aliviar a dor, estancar o sangue. Coloquei um pouco dela para estancar o sangue, porque eu jogava bola descalço e depois fiquei muito aliviado; primeiro porque eu estanquei a ferida e segundo porque eu já tinha dúvidas sobre aquela planta, porque eu já conhecia o antitetânico. Eu duvidei da planta e com isso duvidei do conhecimento que eu aprendi na aldeia pois eu já conhecia a vacina antitetânica e era mais fácil tomar uma injeção, mais seguro, mais confiável do que o que eu tinha aprendido. Então, como estava explicando para eles, e também o faço agora para vocês, como testemunho de que o conhecimento tradicional indígena leva desvantagem nesta relação com o sistema que nos envolve. Como será tratado este tal de conhecimento tradicional? Qual a abordagem que se quer utilizar? É comercial, econômica ou é de preservação, de respeito aos conhecimentos indígenas? E é exatamente essa a nossa preocupação. (Lima, 2003, p. 104- 


\section{0- Considerações finais}

Os conhecimentos tradicionais ou etnoconhecimentos Terena na ampla bibliografia científica e ainda em expansão, tem rica contribuição historiográfica da cultura e tradições desta etnia. Destaca-se na pesquisa a cerâmica Terena em especial da aldeia cachoeirinha em Mato Grosso do Sul (MS), a agricultura e cosmologia. É unânime entre os autores que os Terena têm muito a contribuir na produção científica e na sua arte para as pesquisas científicas.

A grande importância de entendermos a ciência que foi transmitida a gerações do povo Terena na construção da sua identidade como povo é entendermos um pouco da construção de uma nação. Neste sentido, os Terena são parte importante da nossa história como nação, assim como todas as outras tribos brasileiras e o estudo de sua arte na cerâmica, na tecelagem ou do trançado edifica um conhecimento que por gerações sem sido transmitido pelo o povo Terena.

Jafelice chama a atenção da importância do recontar as histórias e estudálas como uma anaálise científica e cultural e que nunca seja apagada:

Os conhecimentos tradicionais sobre as "coisas do céu" e suas relações com as "coisas da terra" são significativos em si, são importantes enquanto aportes histórico-culturais e ainda estão presentes na tradição oral - embora de modo cada vez mais apagado. É um rico conhecimento ambiental e outra visão de mundo que estão em vias de desaparecerem (Jafelice, 2012, p. 102).

No estudo dos etnoconhecimentos Terena podemos ampliar nossa visão para todos os conhecimentos, como mediadores que estabelece novas perspectivas para o conhecimento. O conhecer é estabelecido quando é entendido o conhecimento alheio e todas as suas possibilidades, quando trocas de experiências este conhecimento torna-se mais pródigo e sua vastidão possibilita o entendimento científico da história.

A transmissão do conhecimento que foi descrito na construção do povo Terena auxilia na compreensão da realidade onde se insere e se desenvolve. Assim, etnoconhecimento se apresenta como um caminho alternativo à rigidez científica, sem menosprezar nenhuma das metodologias cientificas existentes, valendo-se 
destas, como ferramentas para uma nova contextualização do conhecimento de outras culturas ou ainda intermediando o tradicional e o cientifico.

Ao estudarmos a cerâmica, a tecelagem, o trançado e a arquitetura do povo Terena, compreendemos sobre a cultura indígena do Brasil e o valor da transmissão do conhecimento regional capaz de conscientizar as próximas gerações sobre a importância cultural, histórica e nacional de compreendermos os modos de vivência dos Terena.

É importante destacar que os Terena têm muito respeito pela ciência e pelos cientistas que os procuram, contudo é importante haver um retorno para as comunidades e suas populações.

\section{0- Referências Bibliográficas}

AFONSO, G.B. Mitos e Estações no Céu Tupi-Guarani. Scientific American - São Paulo: Edição Especial. Etnoastronomia, p. 46-55, 2006.

AFONSO, G.B., SILVA, P.S. O Céu dos Índios de Dourados: Mato Grosso do Sul. Editora UEMS, 2012, 86p.

ALTENFELDER SILVA, Fernando (1948). Mudança Cultural dos Terena. Revista do Museu Paulista. São Paulo, nº 8, V. III. Arashiro e Santos, 2011.

BARCELOS NETO, A. Choses (in)visibles et (im)périssables. Gradhiva, n. 8, 2008.

BARBOSA, D. W. Cerâmica terena. Rio de Janeiro/Funarte: IPHAN, CNFCP, 2003.

BITTENCOURT, Circe Maria Fernandes; LADEIRA, Maria Elisa. A história do povo Terena. Brasília: MEC; São Paulo: USP/CTI, 2000. 156 p.

BROSTOLIN, Marta Regina; CRUZ, Simone Figueiredo, Estilos de aprendizagem e de ensinagem na escola indígena Terena. Construção psicopedagógica, 17(14), 2443. 2009.

CARDOSO, W.T. O céu dos Tukano na escola Yupuri: construindo um calendário dinâmico. 2007. 389 f. Tese (Doutorado em Educação Matemática). Pontifícia Universidade Católica de São Paulo. São Paulo. 2007

CASTILHO, M. A.; SANTOS, M. C. L. F.; GOMES, R. M. Cerâmica Terena: patrimônio imaterial. Tellus, Campo Grande, ano 10, n. 19, p. 231-238, jul./dez. 2010

CASTILHO (201 Castilho, Maria Augusta et al. Artesanato e saberes locais no contexto do desenvolvimento local. Interações (Campo Grande) [online]. 2017, v. 18, n. 3, pp. 191-202. https://doi.org/10.20435/inter.v18i3.1518 ISSN 1984-042X 
CHAVES, Francelina Albuquerque; ALVES, Gilberto Luiz; MATIAS, Rosemary. A produção da cerâmica terena na aldeia cachoeirinha em Miranda, MS. Revista de Ensino, Educação e Ciências Humanas, v. 20, p. 73-80, 2019

CUNHA, M. C. da. Relações e dissensões entre saberes tradicionais e saber científico. Revista USP, [S. I.], n. 75, p. 76-84, 2007. https://doi.org/10.11606/issn.23169036.v0i75p76-84

CUNHA, Fátima Cristina Duarte Ferreira. IDENTIDADE TERENA: a valorização do passado e o olhar para o futuro - estudo relacional de aldeias Terena em Aquidauana e Anastácio 2018. Programa Doutoral em Educação Artística da Universidade do Porto Faculdade de Belas Artes. Tese aprovada em 24 de abril de 2018;

CUNHA, Fátima Cristina Duarte Ferreira; PAIVA, José Carlos. A arte estampada na identidade indígena Terena, Revista Diálogos Interdisciplinares GEPFIP/UFMS/CPAQ, 2018.

DOMINGO, Sandra Ventura e Maria, Elisangela Castedo, Análise do comportamento socioambiental terena por meio de marcadores espaçotemporais: uma contribuição para a conservação da cultura. Interações (Campo Grande) [online]. 2017, v. 18, n. 1, pp. 59-73. https://doi.org/10.20435/1984-042X2016-v.18-n.1 (05) ISSN 1984-042X.

DIAS, C. C. Artes e Ofícios - formas e processos sociais em transformação. In: CONGRESSO BRASILEIRO DE SOCIOLOGIA - DESIGUALDADE, DIFERENÇA E RECONHECIMENTO, 12. 2007, Recife. Anais... Recife: SBS, 2007.

FEHLAUER, Tércio Jacques "Conhecimento Indígena" em perspectiva: performance, habilidades e capacidades agrícolas dos Terena da aldeia Limão Verde (Aquidauana-MS). Tércio Jacques Fehlaver -Florianópolis, 2004. 178f.: il., graf.,tab.

FIALHO, C.F. O percurso histórico da língua e cultura Terena na aldeia Ipegue/Aquidauana/MS. 2010. 54 f. Dissertação (Mestrado em Educação). Universidade Católica Dom Bosco, Campo Grande, 2010.

FRAXE, T. J. P.; PEREIRA, H. S.; Witkoski, A. C. (organizadores). Comunidades ribeirinhas amazônicas: modos de vida e uso dos recursos naturais - Manaus: EDUA,2007.

GALDINO, L. A Astronomia Indígena. São Paulo: Nova Alexandria. 2011, 93p.

GEERTZ, Cliff ord. A transição para a humanidade. Rio de Janeiro: Fundo de Cultural, 1996.

GRAZIATO, V.P.P. Cerâmica Kadiwéu processos, transformações, traduções: uma leitura do percurso da cerâmica Kadiwéu do século XIX ao XXI. São Paulo: USP, 2008. 
GOMES, L. S.; KABAD, J. F. A produção da cerâmica pelas mulheres Terena: interfaces entre cultura material, gênero e território tradicional. in: reunião brasileira de antropologia, 26, 2008, porto seguro. anais... UFBA: Porto Seguro, 2008;

GOMES, L.S. A produção da cerâmica pelas mulheres Terena: interfaces entre cultura material, gênero e território tradicional. In: REUNIÃO BRASILEIRA DE ANTROPOLOGIA, 26, 2008. Porto Seguro. Anais... Porto Seguro: UFMS: 2008.

GOMES, Luciana Scanoni. Do cru. A vida oculta da cerâmica terena. Tellus, Campo Grande: Tellus, ano 16, n.31, pp.163-180, 2016.

GODOY, A.F. A cerâmica Terena e sua produção na arte indígena do Mato Grosso do Sul. Aquidauana: Universidade Federal de Mato Grosso do Sul, 2001.

JAFELICE, L. C. (Coord.). Encontro de pesquisa A - Astronomia cultural. In: LEITE, C.; BRETONES, Paulo S. (Ed.). SIMPÓSIO NACIONAL DE EDUCAÇÃO EM. ASTRONOMIA, II, São Paulo: 2012. Anais... São Paulo: IFUSP, 2013. Disponível em: http://snea2012.vitis.uspnet.usp.br/sites/default/files/SNEA2012_EP_A_Astronomia\% 20Cultural.pdf

JESUS, Naine Terena. Kohixití-kipaé, a dança da ema - memória, resistência e cotidiano Terena. 2007. Dissertação (Mestrado em Arte) - Universidade de Brasília, Brasília, 2007.

LANGHI, R. Aprendendo a ler o céu: Pequeno guia prático para a Astronomia Observacional. Campo Grande: Ed. UFMS, p. 88-89, 2011.

LIMA, Tânia Andrade. Cerâmica indígena brasileira. In: RIBEIRO, Darcy (Ed.). Suma etnológica brasileira. Petrópolis, RJ: Vozes, 1987. v. 2: Tecnologia indígena.

LIMA, André. (2003). Quem cala consente?: subsídios para a proteção aos conhecimentos tradicionais/organizadores André Lima, Nurit Bensusan. -- São Paulo: Instituto Socioambiental, -- (Série Documentos do ISA; 8)

MATO GROSSO DO SUL [Estado]. Decreto n. 12.847, de 16 de novembro de 2009. Cerâmica Terena - MS - registro do patrimônio imaterial. Campo Grande, MS, 2009.

MELIÁ, Bartolomeu. Educação indígena na escola. Conferência ministrada no I Congresso Internacional de Educação Indígena. Dourados (MT), 23-27 março, 1998.

MIRANDA, do C. Claudionor. Territorialidade e Práticas Agrícolas: premissas para o desenvolvimento local em comunidades Terena. Dissertação de Mestrado.Universidade Católica Dom Bosco-UCDB. Campo Grande/MS. 2006. $122 p$.

MCKINLEY, E., A.; SMITH, L., T. Handbook of Indigenous Education: p. 1-15. 2019.

OBERG, Kalervo. A economia Terena no Chaco. Terra Indígena - UNESPAraraquara. São Paulo: $n^{\circ}$ 55, 1990. 
OLIVEIRA, E.D. Registro de Lendas e Estórias Terena, Campo Grande: Ed. Mória, 2003, 84p.

OLIVEIRA, Eder Alcantara, 2016. Uma apresentação iconográfica dos rituais religiosos/culturais Terena na Aldeia Buriti, MS TELLUS ano 16, n. 30, jan./jun. 2016 Iconografia

OLIVEIRA, E. J.; PEREIRA, L.M., Perícia antropológica, histórica e arqueológica da Terra Indígena Terena de Buriti. Justiça Federal - Campo Grande-MS: P. 242. 2003.

POSEY, D. Manejo da floresta secundária, capoeiras, campos cerrados (Kayapó). In: Sumula Ełnológica brasileira. Petrópolis: Vozes, 1986, p. 173-185.

ROUÉ, M. "Novas perspectivas em etnoecologia: "saberes tradicionais" e gestão dos recursos naturais". In: Diegues, A. C. Etnoconservação: novos rumos para a proteção da natureza nos trópicos. São Paulo: Hucitec, 2000.

ROHDE, Richard. Algumas notícias sobre a tribo indígena dos Terenos. Terra Indígena, UNESP, Araraquara, n. 55, p. 11-17, abr./jun. 1990.

ROMANOWSKI, J. P.; ENS, R. T. As pesquisas denominadas do tipo "Estado da Arte". Diálogos Educacionais, v. 6, n. 6, p. 37-50, 2006.

RIBEIRO, Berta G. A civilização da palha: arte do trançado dos índios do Brasil. São Paulo: USP, 1980. P. 452.

RIBEIRO, Berta G. O índio na cultura brasileira: pequena enciclopédia da cultura brasileira. Rio de Janeiro: UNIBRADE- UNESCO, 1987.

SOUZA, Sandra Cristina de. Mulheres Terena: história e cotidiano. 2000. $82 f$. Dissertação (Mestrado em História) - Pontifícia Universidade Católica de São Paulo, São Paulo, 2000.

SÁ, Romulo C. (Organizador. RELATÓRIO FINAL DO INVENTÁRIO DA CULTURA MATERIAL TERENA - CR CAMPO GRANDE-MS), Funai, Museu do Índio, 2012.

SEIZER da Silva, Antonio Carlos. Kalivôno Hikó Trenoe: sendo criança indígena Terena do século XXI: vivendo e aprendendo nas tramas das tradições, traduções e negociações. Campo Grande; UCDB, 2016.

SILVA, A. VIDAL L. O Sistema de objetos nas sociedades indígenas: arte e cultura material. MEC, 1995.

SILVEIRA, Maria Isabel S. C. A tecelagem manual e o design têxtil: um diálogo entre o ancestral e o industrial. $9^{\circ}$ Colóquio de Moda, 2013.

STEIN, Stanley J. Origens e evolução da indústria têxtil no Brasil - 1850/1950. Rio de Janeiro: Editora Campus LTDA, 1979. 
TERENA, Jorge Miles da Silva. A biodiversidade do ponto de vista de um índio. GTAA, 2003.

VIETTA, Katya. Os "valores" da cerâmica terena campo-grandense: um silencioso patrimônio inatingível. Cadernos do Lepaarq, Pelotas, n. 24, v. 12, p. 98-132, 2015. 